\title{
"ENSINO EM LIBRAS NA MODALIDADE EAD: UM ATENDIMENTO AO SERVIDORES DO MINISTÉRIO PÚBLICO DE GOIÁS”
}

GOIÂNIA/GO AGOSTO/2018

\author{
LEANDRA PEREIRA DA SILVA - SENAI GO - leandra.senai@sistemafieg.org.br \\ ROBERSON CARDOSO FEITOZA - NIEAD GO - robersoncardoso.sesi@sistemafieg.org.br
}

Tipo: Relato de Experiência Inovadora (EI)

Categoria: Métodos e Tecnologias

Setor Educacional: EDUCAÇÃO CORPORATIVA

\begin{abstract}
RESUMO
O presente artigo é um relato da experiência do ensino em Libras através da modalidade EaD aos servidores do Ministério Público de Goiás, e teve com finalidade trabalhar competências essenciais nos servidores para realizar o atendimento aos surdos, aumentando a qualidade do serviço público prestado. Com esse propósito levantamos alguns aspectos importantes para a consolidação do ensino desta língua por meio da educação a distância, haja vista que essa modalidade tem oportunizado por meio de suas ferramentas o acesso à educação em diferentes níveis, além de flexibilizar a realização de treinamentos e reduzir o deslocamento e despesas com hospedagens e diárias. Neste sentido, 0 desenvolvimento de conteúdo em Libras foi consubstanciado na análise do contexto e público-alvo, a partir dos objetivos da aprendizagem definiu uma ação educacional mais específica para o atendimento do Ministério Público de Goiás.
\end{abstract}

Palavras-chave: Educação a Distância; Treinamento em Libras; Ação Educacional 


\section{1 - INTRODUÇÃO E OBJETIVOS}

O seguinte artigo apresenta uma proposta de criação do curso de Libras na modalidade EaD oferecido aos servidores do Ministério Público do Estado de Goiás. Através do atendimento constatamos que treinamentos na modalidade de ensino são eficazes quando bem estruturados, e para que isso ocorra é necessário realizar um levantamento, afim de identificar detalhes na formatação dos cursos que explore o universo de possibilidades da educação a distância.

A educação a distância é uma modalidade de ensino que cresce e expande em todo território nacional e internacional, este veículo de aprendizagem vem tornado acessível o conhecimento a uma gama de estudantes que não fazem o perfil do ensino presencial ou não possuem acesso a ele em sua localidade. A EaD por ser uma modalidade de ensino cujo o veículo principal de comunicação é o cyber espaço, permite a formação de grandes grupos espalhados por diversas regiões.

Por outro lado, expansão da Educação a Distância está diretamente ligada aos avanços das tecnologias de informação e comunicação, e essas tecnologias amplia as técnicas pedagógicas e favorece a criação de cursos, pois são ferramentas de apoio ao processo de ensino-aprendizagem, principalmente quando existe mediação (educando e educador) e a escolha do melhor projeto vai determinar o sucesso ou o fracasso do curso.

Para Moran (1994), uma das consequências deste cenário é uma nova dimensão na área do conhecimento. O uso das novas tecnologias a serviço da educação permite que um universo cada vez maior de pessoas tenha acesso a informação em uma velocidade que se aproxima do instantâneo.

Visando suprir essa crescente por educação o número de instituições que desenvolvem cursos por meio da modalidade EaD vem crescendo, entretanto muitas desenvolvem cursos utilizando materiais didáticos baseados apenas em textos e vídeos, desconsiderando as práticas de ensino mediadas pelo uso de tecnologias de informação e comunicação, contudo quando se trata do ensino em Libras a distância deve priorizar, a teoria e a prática. De acordo com Castro Júnior (2014), é preciso considerar a Libras como uma língua dinâmica, que sofre alterações no decorrer do tempo e do espaço, e no próprio processo linguístico - interativo. Por isso, ensinar Libras por meio da educação a distância aos servidores do Ministério Público de Goiás requereu do SENAI de Goiás uma capacidade organizacional e metodológica pertinente aos desafios criados pelo aprendizado de uma língua, no caso a Língua Brasileira de Sinais (Libras). 
Por meio de uma metodologia aplicada ao ensino em Libras, levantamos as necessidades educacionais dos cursistas com o propósito de garantir condições de usar a língua como meio de comunicação, tendo como principal objetivo prepará-los para enfrentar as necessidades linguísticas, psicológicas e socioculturais do surdo, ensinando noções comunicativas para o primeiro contato, proporcionando a interação entre ouvintes e surdos. Assim, apresentamos as mudanças sociais e as diferentes formas de identidade e a cultura da comunidade surda para que os servidores entendessem a importância do estudo deste idioma para auxiliar no atendimento da pessoa surda.

\section{LIBRAS LINGUA OU MÍMICA?}

Visando o acesso à informação para as pessoas surdas, propondo uma comunicação efetiva entre surdos e ouvintes o Decreto № 5.626 de 22 de dezembro de 2005, que regulamenta a Lei o 10.436, de 24 de abril de 2002 entrou em vigor e a Língua Brasileira de Sinais (libras) se tornou reconhecida nacionalmente, e o surdo respeitado pela Língua que utiliza, valorizando sua forma de comunicação e expressão na inserção social dentro dos diversos setores onde a comunicação se faz necessária para aquisição de bens de informação, educação, instrução, acessibilidade, acontecimentos, lazer e serviços.

A Língua Brasileira de Sinais recebeu grande reconhecimento, em nosso país, nos últimos anos, foram desenvolvidas pesquisas, atividades culturais, discussões pedagógicas, políticas públicas cada vez mais voltadas para a área da surdez e sua comunicação, no entanto, existem muitas dúvidas a respeito desta língua, dos seus usuários e dos profissionais que trabalham como interpretes desta língua, gerando uma série de crenças que não correspondem à realidade. Isso acontece pois, por muitos anos, a falta de informação levou os não usuários deste idioma, por questões filosóficas, religiosas, políticas e econômicas, a supor o que seria libras, imaginando que não se tratava de uma língua e sim de uma sequência de gestos ou mimicas que representa-se apenas o que é icônico[1]. Talvez você mesmo pense que essas ideias sejam verdadeiras, por fruto do desconhecimento. Apesar do impacto dessas concepções, as pesquisas avançaram muito e nos mostraram que tais ideias são equivocadas. Uma pessoa com deficiência deve ser vista como pessoa antes de sua deficiência. Para os surdos, sua identidade e língua são fatores que os representam e por onde demonstram seus inúmeros potenciais.

Assim, a libras é a língua brasileira de sinais, natural dos brasileiros surdos, usada por grande parte da comunidade surda do nosso país, entretanto é importante esclarecer que libras não é mimica e sim uma língua, pois cada país possui a sua, por exemplo em 
Portugal usa-se a língua gestual portuguesa (LGP) que é diferente da libras.

A libras, assim como em qualquer outra língua é composta por níveis linguísticos como: fonologia, morfologia, sintaxe e semântica. Essa língua pertence à modalidade visualespacial, pois seus usuários naturais são os surdos. Sendo assim, a comunicação é recebida através do sentido da visão e enviada por sinais e expressões corporais utilizando o espaço físico, sendo diferente da língua portuguesa e todas as línguas orais que pertencem a modalidade oral-auditiva, ou seja, utiliza o sentido da audição para receber a mensagem e a fala para enviar uma mensagem.

Para se comunicar em libras é necessário que o falante entenda que como nas línguas orais essa língua também possui uma estrutura que são os sinais, as expressões faciais, as marcações no espaço e no corpo do falante. Em quanto em língua portuguesa a comunicação se dá por meio de frases com palavras consecutivas, nas línguas de sinais as palavras são apresentadas de forma não linear, como em blocos. Ao analisar essa estrutura podemos perceber que muitas vezes em libras uma frase pode ser dita mais rápida do que em português, visto que sua organização é feita em blocos e não de forma linear.

Geralmente as pessoas que não conhecem os surdos ou as línguas de sinais acabam acreditando ou mesmo disseminando informações irreais a respeito da comunidade surda e da libras. Isso ocorre, pois por muitos anos os surdos eram tidos como incapazes gerando em torno desta comunidade questões filosóficas, religiosas, políticas e econômicas que emitiam conceitos que não correspondem com a realidades deste povo. Hoje a comunicação permite que a comunidade surda desmistifique estes mitos, baseados em estudos e pesquisas científicas.

Ao se propor estudar um novo idioma é fundamental conhecer a cultura e costumes dos usuários desta língua, em libras não seria diferente, pois entender esses costumes ajuda muito a compreender como utilizar uma língua espaço-visual, ou seja, utilizar as mãos para formar sinais em um espaço, em que cada sinal possui significado e significância para uma comunicação. Daí a necessidade de abordar aspectos conceituais e dados, a fim de sensibilizar os participantes para proposta do curso. Com esse objetivo sugerimos o fórum para tratar como poderia ser a comunicação entre surdos e ouvintes, e a importância de saber a língua de sinais, quais as vantagens para o ouvinte e também para o surdo ao dominar a Libras.

\section{3 - DESIGNER INSTRUCIONAL E TUTORIA DO CURSO DE LIBRAS EaD}


A aprendizagem se dá por diversas formas, cada indivíduo possui e apresenta uma maneira própria de aprender, a forma individual de adquirir conhecimento é definida como Estilo de Aprendizagem, vale ressaltar que não se trata do que o indivíduo aprende e sim a forma que ele utiliza durante o aprendizado. Na educação a distância a aprendizagem tem o ciberespaço como principal veículo de interação e troca de conhecimento. Para Levy (1998, p.67), O ciberespaço é definido como um mundo virtual. Esse mundo não é palpável, mas existe de outra forma, outra realidade. O ciberespaço existe em um local indefinido, desconhecido, cheio possibilidades.

Pozo (1998, apud SUCUPIRA, 2007), diz que o conceito de aprendizagem surge com os behavioristas. Esta linha teórica de estudo afirma que o conhecimento é proveniente dos sentidos e do comportamento humano e é estudado como um conjunto de elementos unidos por regras sintáticas e por princípios de correspondência. Pode-se destacar dois grandes grupos teóricos relativos à aprendizagem: 0 das teorias comportamentais e 0 das teorias cognitivas.

Comportamentalista: também conhecida como, empirista ou behaviorista, $\mathrm{O}$ aprendiz é, então, entendido como uma tábula rasa, que recebe estímulos externos, estabelece uma associação e é condicionado a fixar o estímulo recebido de forma passiva e incontestável (POzO,1998, apud SUCUPIRA,2007). Assim, não são considerados os valores dos estudantes nem suas diferenças individuais.

A tarefa do professor, nesta teoria, se resume à transmissão do conhecimento esperando que seus alunos respondam, através do reforço condicionado, o desempenho esperado. O aluno realiza as atividades propostas repetindo as informações do professor, em uma atitude de passividade. (SUCUPIRA,2007)

Cognitivista: esta linha teórica sobre a teoria da aprendizagem não considera o conhecimento sendo totalmente inato nem determinado pelo meio. Para Piaget (1990, p.7-8, apud SUCUPIRA,2007, p.29) O conhecimento não procede, em suas origens, nem de um sujeito consciente de si mesmo, nem de objetos já constituídos (do ponto de vista do sujeito) que se lhe imporiam: resultaria de interações que se produzem a meio caminho entre o sujeito e o objeto, e que dependem, portanto, dos dois ao mesmo tempo, mas em virtude de uma indiferenciação completa e não de trocas entre formas distintas. Nesta concepção, a interação entre professor e aluno deve ser descentralizada da figura de poder do professor. O papel do docente é estimular no aluno a busca por encontrar respostas por si mesmos.

Pessanha e Struchiner (2005), apud Santos (2006) nos fala sobre categorias teóricas 
para a construção de práticas metodológicas de ensino-aprendizagem na web e estabelece três categorias teóricas para estas práticas, interatividade, cooperação e autonomia, a partir destas categorias é possível discutir um modelo de aprendizagem em que o aluno se torna responsável pelo seu desempenho, considerando o professor neste cenário como um facilitador/ mediador e o aluno como autônomo do processo de ensino-aprendizagem.

Os procedimentos metodológicos adotados neste trabalho se configuram na pesquisa descritiva e é caracterizada pela observação visto que os autores estão imersos nesse universo da proximidade com o EaD e os processos tradutórios em Libras (mediação e aprendizagem). Os instrumentos selecionados baseiam-se na coleta de informações através do levantamento inicial e na execução das turmas e avaliação e análise dos resultados.

Ao realizar o levantamento das necessidades educacionais, para o desenvolvimento do curso de libras para esta turma do Ministério Público, verificamos a capacidade de conexão em algumas comarcas, pois a falta poderia resultar em elementos de restrição ao acesso ao curso, desta forma identificamos se a infraestrutura existente era compatível com as condições relacionadas para execução das atividades. Quanto a característica cognitiva dos servidores avaliamos os conhecimentos prévios e o perfil dos participantes por turma. Com isso, adequamos o desenho do contexto, as mídias, os níveis de abstração, modo de interação, estilos de linguagem, tempo de instrução, bem como estruturamos apoio necessários para a aprendizagem e alinhamos o tipo de abordagem. Neste contexto, foi feito uma sondagem inicial com informações repassadas pelo Ministério Público para propor um desenho de curso que melhor se adaptasse aos cursistas.

Em contato com a promotoria foi informado que a turma seria composta por 60 servidores de várias comarcas do interior, as características dos servidores que iria compor a turma e quais seriam as principais necessidades do uso da libras. Assim, nossa proposta foi apresentar situações cotidianas para aprendizagem deste idioma. Após conversas com Recursos Humanos do MPGO foi nos passado o requisito de ingresso dos servidores e assim conseguimos identificar o nível de formação e instrução dos participantes, que, em regra eram lotados na função de secretários e responsáveis por auxiliar no planejamento, execução e avaliação de planos, projetos, programas e pesquisas da administração superior do Ministério Público e dos órgãos de execução, além de auxiliar no atendimento ao público, entre outras funções.

Em relação a formação os participantes possuíam nível superior e conhecimento sobre 
tecnologias e pacote office. Com todas as informações coletadas foi iniciado o desenho instrucional do curso, o qual teve como reflexão as seguintes perguntas que nortearam o início do processo de desenvolvimento: o que significa "saber libras"? Como podemos ter certeza de que assimilaram o conteúdo? Que tipo de atitudes terão que assumir? Que tipo de habilidades terão que adquirir? A partir desta reflexão definimos um designer instrucional contextualizado e optamos por utilizar a plataforma de ensino 0 moodle.

As aulas foram divididas em 8 módulos, para cada módulo a seguinte estrutura: Conteúdo scorm[2] com vídeos, material complementar, videoaula explicativa, questões objetivas e/ou questões discursivas, além de fóruns temáticos com produção de vídeos e desafio final simulando uma situação real de aprendizagem para melhor fixação do conteúdo abordado.

Fonte: O autor

O curso foi construído de tal forma que a fundamentação teórica seria feita a distância, através do ambiente virtual de aprendizagem do SENAI com a carga horária de 160 horas, com apoio de monitoria e tutoria. Após definição do professor foi realizado treinamento do profissional na metodologia a distância com o curso Formação de Tutores e ambientação dentro do moodle.

A aula inaugural foi realizada de forma síncrona em uma videoconferência via Skype com duração de 45 minutos, onde os alunos puderam conhecer a tutora/professora, bem como entender como aconteceria o processo de ensino aprendizagem por meio da educação a distância. Um dos limitadores para essa ação foram os bloqueios existente da rede interna do Ministério Público que não permitiu o acesso de todos os servidores a ferramenta.

O conteúdo foi organizado e estruturado para que servidores dedicassem 1(uma) hora de estudo diária, de segunda a sexta-feira, perfazendo a carga horária do curso.

O conteúdo basilar foi disponibilizado aos servidores no Ambiente Virtual de Aprendizagem (AVA) do SESI/SENAI, contudo usamos também outras ferramentas com o canal do youtube, o aplicativo Hand Talk, vídeos chamadas e redes sociais. No AVA o participante teve acesso ao conteúdo on-line, aos fóruns, biblioteca virtual, exercícios de fixação e publicação de atividades avaliativas. Na data prevista os participantes receberão E-mail de boas-vindas onde foram informados do login e senha de acesso ao AVA, bem como um manual de acesso para facilitar a navegação. 
No AVA os alunos tiveram acesso ao plano de estudos e um guia com as orientações gerais sobre a proposta da turma. A primeira semana de aula foi desenvolvida uma ambientação que durou 7 (sete) dias, neste momento eles foram orientados sobre questões de acesso, manuseio do ambiente virtual e solucionamos problemas relacionados a senha e usuário.

\section{5 - CONSIDERAÇÕES FINAIS}

A libras é uma língua e como qualquer outra sua aquisição depende de muito esforço e dedicação, o que implicitamente é uma das qualidades esperadas de quem estuda na modalidade $\mathrm{EaD}$, por isso o curso foi desenvolvido nesta linha de pensamento, propondo situações onde os servidores pudessem vivenciar e comunicar neste idioma, portanto podemos afirmar que os participantes encontraram durante o curso desafios que proporcionaram o desenvolvimento de novas habilidades e competências. Com isso, percebemos atitudes qualificadas para uma comunicação em libras de forma a atender a necessidade de comunicação requerida pelo Ministério Público. Assim, o projeto alcançou seu objetivo, pois verificarmos por meio dos feedbacks dos servidores e constatamos isso também no último desafio do curso onde os participantes realizaram a primeira interpretação para a comunidade surda, isto é, eles escolheram uma música e produziram vídeos com a interpretação na versão em libras.

\section{REFERENCIAS}

MORAN, J. M. Novos caminhos no ensino à distância. In: Informe CEAD Centro de Educação a Distância. SENAI, Rio de Janeiro, vol. 1, n. 5, out./nov./dez. 1994

CASTRO JÚNIOR, Gláucio de. Projeto varlibras. 2014. 259 f. Tese (Doutorado em Linguística) - Universidade de Brasília, Brasília, 2014.

KENSKI, Vani Moreira. Tecnologias e Ensino presencial e a Distância. Campinas, SP: Papirus, 2003. (Série Prática Pedagógica)

LEVY, Pierre. As Tecnologias da Inteligência. São Paulo: Loyola, 1998.

SUCUPIRA,Maria Judith,2007. Aprendizagem e Tutoria In: SENAC. Curso de Especialização em Educação a Distância-vol.1versão 4.0,2007.

LEFFA, V. J. (org.). Autonomy in language learning. Porto Alegre/RS: Editora da Universidade UFRGS, 1994. 395p. 
[1] Icônico: que representa o modelo com fidelidade sem artifícios, ou seja, que mantém uma relação de semelhança com o referente.

[2] Scorm: trata-se da sigla para a nomenclatura em inglês "Sharable Content Object Reference Model", que pode ser traduzida como "Modelo de Referência de Objeto de Conteúdo Compartilhável" "e um padrão para auxílio na comunicação de uma plataforma LMS para criação de aulas interativas. 